\title{
Involuntary automatic processing in color-naming tasks
}

\author{
JOAN REGAN \\ University of California, Berkeley, California 94035
}

\begin{abstract}
The automatic processing hypothesis holds that very familiar items are processed involuntarily, and two color-naming experiments were designed to test this further. Experiment 1 employed words as written stimuli and focal and nonfocal colors as inks. Supporting the automatic processing hypothesis, neutral words delayed color naming, indicating that their representations were activated involuntarily. There was no interaction of ink type and written item conditions. Experiment 2 employed single letters as written stimuli. Color-name initials delayed color naming when incompatible with the color and facilitated it when compatible, suggesting that, although letters may be processed involuntarily, the way in which they are encoded is influenced by the cognitive context. The data from both experiments were discussed in relation to current interpretations of Stroop effects.
\end{abstract}

Several theorists have suggested that there are two fundamentally different modes of information processing, automatic and nonautomatic (LaBerge \& Samuels, 1974; Posner \& Snyder, 1975; Schneider \& Shiffrin, 1977). They describe automatic processing as developing with practice, occurring involuntarily, and being independent of any limited capacity central mechanism. An example of such automatic processing is reading a word. For the child, reading is initially laborious and slow, and may proceed on a letter-byletter basis. For the adult skilled reader, reading requires little effort, is fast, and can be performed concurrently with other activities, as when one reads a billboard while driving. In reading a word, the automatic processing theorists suggest that an internal memorial representation of the word is automatically activated when the word is presented, and that such a representation contains information about the word's pronunciation, meaning, and association to other concepts.

The focus of the present experiments is on the involuntary nature of automatic processing. Experiment 1 examined the involuntary processing of words. Experiment 2 employed single letters. Theories of automatic processing suggest that people have no direct control over automatic processes, that no decision making is involved, and that the processing sequence will run to completion whether or not it

This paper was written while the author was at NASA, Ames Research Center, Moffett Field, California, under a National Research Council Research Associateship. I would like to express thanks to Eleanor Rosch, who advised on the experiments and commented on the article, and to Stephen Palmer and Loy Braley, who commented on earlier versions. Requests for reprints should be sent to Joan Regan, Department of Psychology, University of North Carolina, Greensboro, North Carolina 27412. is compatible with the person's intention. Posner and Snyder (1975) have indicated that the Stroop phenomenon is a prime example of automatic processing without intention.

The Stroop task requires people to name the color ink in which a word is printed as quickly as they can. This task is difficult to do when the word is a color name that is different from the ink color, e.g., "RED" written in blue ink. Posner and Snyder (1975) assert that an interference effect (relative to a control condition) when word and ink color are incompatible indicates that subjects cannot ignore the word even though it would be advantageous to do so. Since color words may be primed by the nature of the task which requires subjects to repeat color names continuously, a stronger case for the automatic processing hypothesis would be provided by an interference effect when the words are neutral words, i.e., not related to color. (The priming effect may also be an automatic process, but this will not be investigated here.) Were a neutral word to interfere with color naming, it would indicate that the reading response is automatic in that subjects cannot avoid processing the word. If neutral words do not provide interference, it would indicate that the conflict in the Stroop task occurs only because of the priming produced by color naming, rather than that all very familiar items are processed automatically.

The original method for the Stroop test involved presenting many items together on one large card, the dependent variable being time to name all items on the card. Types of written items (e.g., color words, color-related words) were manipulated between cards, so that any one card contained only items from one condition. Using this procedure, Klein (1964) found interference with neutral words. Keele 
(1972) found no effect in a discrete trial (tachistoscopic) procedure requiring a buttonpress response. Since automatic activation of the representation of a neutral word would not elicit any response incompatible with a manual response, such activation would not be evident in the manual task. However, using the discrete-trial procedure with the standard vocal response, Hintzman, Carré, Eskridge, Owens, Shaff, and Sparks (1972) found no interference with neutral words and concluded that such an effect did not exist with the discrete trial procedure. This study employed a control that consisted of color-word anagrams (e.g., "RDE," "BEUL") beginning with the same first letter as the color word. This type of item may not have provided a sufficiently neutral control against which to compare color or neutral words. The task requires subjects to identify repeatedly and/or say aloud the names of a small set of colors. Given the similarity of the anagram to the color word (e.g., "RDE" to "RED"), it is probable that subjects recognized the letter strings as being anagrams of color words and that they were processed in their relationship to color. The neutral words also began with the same first letter as the color words and were the same length, e.g., "RAT." Neutral words that are visually dissimilar to color words should not be primed by the color-naming task. One purpose of Experiment 1 was to see if interference did occur with such neutral words when compared against a control of Xs.

The question of automatic processing of neutral words in the Stroop task cannot be considered separately from theoretical explanations of the interference effect with color words. The perceptual conflict explanation (e.g., Hock \& Egeth, 1970) holds that the word processing is primary and disrupts or delays processing of the color. The response conflict position (e.g., Keele, 1972) states that both word and color are processed in parallel up to response initiation and that interference occurs because of two incompatible responses (see Dyer, 1973 for a review). The automatic processing hypothesis belongs to the class of response conflict positions (see Posner \& Snyder, 1975). The word is encoded, its meaning determined, and a motor program activated in parallel with color processing. There is no interference until the response output point.

In supporting the response conflict model, Dyer (1973) has suggested that there should be some optimal processing rate for colors relative to words that would maximize interference. He argued that fast word processing relative to color processing would reduce interference because the reading response can be gotten out of the way more quickly. In the first of these present experiments, Dyer's prediction was tested by including a variable that would influence perceptual encoding of the color. The variable was that of goodness-of-category membership. Previous research (Rosch, 1975) has demonstrated that color categories have a central focus and a continuous distribution toward the periphery of the category. Colors close to the focal point are the best examples of the category, and those farthest from the focal point are the poorest examples. Experiments have shown that focal colors are learned more readily than nonfocal colors (Heider, 1972; Mervis, Catlin, \& Rosch, 1975) and are more perceptually salient for children (Heider, 1971). If focal colors are perceptually more salient, one should expect that they will be encoded and named more rapidly than nonfocal colors. If the relative speeds of color and word processing determine the amount of interference, as implied by the response conflict model, then there should be a different pattern of interference for focal and nonfocal colors.

The major purpose of the first experiment, then, was to test if neutral words are processed involuntarily. To this end, the Hintzman et al. (1972) study was replicated with a control of Xs. In addition, color processing time was manipulated by using colors that were either good or poor category members.

The second experiment investigated the influence of single letters on color naming. Letters per se are irrelevant to the color-naming task, and subjects should be able to ignore them unless the letters are processed automatically.

\section{EXPERIMENT 1}

\section{Method}

Design. The design of the experiment was a 2 by 3 by 6 by 6 repeated measures factorial, representing focal/nonfocal colors; three ink colors to be named: red, green, and blue; six blocks and six types of written item conditions: (1) control: five Xs in a horizontal row, (2) neutral words, (3) color-related words compatible with the ink color (e.g., "GRASS" written in green ink), (4) color-related words incompatible with the ink color (e.g., "SKY" written in green ink), (5) color names incompatible with the ink color (e.g., "BLUE"' written in green ink), and (6) color names compatible with the ink color (e.g., "GREEN" written in green ink).

Materials: Inks. Originally, four color categories were selected for use in the experiment: red, green, blue, and yellow. Seven pure and combined samples from each color category were selected from purchased inks. A patch of each color was marked on index cards and 10 students inspected a random ordering of the cards. Each card was numbered, and on another numbered sheet the student wrote the name he thought best described the color patch. The subjects were instructed not to use unusual names such as magenta. After the spontaneous naming was completed, each subject rated the cards for goodness-of-category membership on a 7-point scale. The final selection of colors to be used in the experiment was limited to those colors named red, green, blue, and yellow by all 10 subjects. Of these colors, the patches getting the highest and lowest ratings were selected as representing good and poor examples of the category. The mean ratings for the colors selected were as follows, showing the rating for focal colors first: red, 6.7, 2.9; blue, 5.8, 2.1; green, 5.8, 2.0; yellow, 6.7, 2.9. 
Those colors getting the lowest ratings were all desaturated colors. During pilot work with the selected colors, it became clear that the good example, yellow, was too light to be seen clearly in the tachistoscope, so the experiment was run without any examples of yellow. The colors finally used as focal colors were Skrip Permanent Red, Pelikan Special Blue, and FW April Green. The nonfocal colors had some Pelikan Black and Pelikan White added to Kohinoor Transparent Red, Kohinoor Transparent Blue, and FW April Green.

Written items. The color-related words were those nouns given first as an associate to the color in the Palermo-Jenkins norms (1964). The words were "SKY," "GRASS," and "BLOOD." The neutral words were chosen to have no association to any color on an intuitive basis, and to be approximately equivalent in frequency to the color-related words according to the KuceraFrancis (1967) norms. The words selected were "WAGE," "GAME," and "CHAIN." (There were no suitable three-letter nouns to match "SKY.") All written items were centered on $3 \times 5$ in. white cards which were then mounted on $6 \times 9$ in. cards for insertion in the tachistoscope. A Leroy lettering set was used to form words in capital letters, $1.7 \mathrm{~cm}$ high. The written stimuli varied from 4.5 to $7.5 \mathrm{~cm}$ in width.

Stimuli for each condition were generated by using each ink color and good and poor examples equally of ten. Altogether, there were six decks of cards with 36 items per deck, representing six examples of each written item condition, three in good-example colors and three in poor examples. Within each deck, presentation order was random, with the following constraints: no item was adjacent to the same ink color, same word, or word related to the ink color or ink color related to the word. For example, the word "RED" written in blue ink was neither preceded nor followed by any item in blue or red ink, or by any word related to the colors red or blue. The decks of cards were numbered 1-6, and each subject was assigned to a starting deck with random numbers so that each deck was used first an equal number of times.

Procedure. All stimuli were presented in one field of an Iconix tachistoscope equipped with Sylvania F $615 / \mathrm{CW}$ fluorescent bulbs and with the intensity dial set at 5 . The subjects were shown samples of the stimuli, and were given 10 practice trials before reaction times (RTs) were recorded. For each trial, the experimenter pressed a button which exposed the stimulus and started a clock. The subject's voice stopped the clock by means of a voice-activated relay. The stimulus remained in view until the subject responded. If the subject made an error, the stimulus card was placed at the bottom of the deck and presented later, so that all RTs reflected correct responses. The subjects rested after every 18 trials. During this period, the experimenter added up the RTs and told the subject the average RT for that set of trials. Testing resumed whenever the subject felt ready. The intertrial interval was approximately 4 sec.

Subjects. Eighteen undergraduate students at the University of California, Berkeley, participated to fulfill a course requirement. All were screened for color blindness before the start of the experiment.

\section{Results}

Mean RTs for all the written item conditions and the corresponding interference/facilitation scores are shown collapsed over blocks and ink colors in Table 1, and collapsed over goodness of example and blocks in Table 2.

Analysis of variance revealed main effects of goodness of example $[F(1,17)=50.0, p<.001]$, written items $[F(5,85)=107.11, p<.001]$, blocks $[F(5,85)$ $=8.30, \mathrm{p}<.001]$, and ink color $[\mathrm{F}(2,34)=50.41$, $\mathrm{p}<.001]$. In addition, the written item factor interacted both with ink color $[F(10,170)=10.80$, $\mathrm{p}<.001]$ and with blocks $[\mathrm{F}(24,425)=2.32$, $\mathrm{p}<.001]$. No other effects were significant. The Ink Color and Written Item interaction is shown in Table 2 and the Written Item by Block interaction is displayed in Figure 1.

Table 1

Mean Reaction Times to Color Naming: Focal-Nonfocal Colors, Experiment 1

\begin{tabular}{|c|c|c|c|c|c|c|}
\hline \multirow[b]{3}{*}{$\begin{array}{l}\text { Control } \\
\text { Neutral Words } \\
\text { Incompatible Color Related Words } \\
\text { Compatible Color Related Words } \\
\text { Incompatible Color Words } \\
\text { Compatible Color Words }\end{array}$} & \multicolumn{6}{|c|}{ Goodness of Color } \\
\hline & \multicolumn{2}{|c|}{ Focal } & \multicolumn{2}{|c|}{ Nonfocal } & \multicolumn{2}{|c|}{ Mean } \\
\hline & $\begin{array}{l}591 \\
626 \\
663 \\
609 \\
762 \\
562\end{array}$ & $\begin{array}{l}(-35) \\
(-72) \\
(-18) \\
(-171) \\
(+29)\end{array}$ & $\begin{array}{l}621 \\
654 \\
691 \\
641 \\
791 \\
592\end{array}$ & $\begin{array}{l}(-33) \\
(-70) \\
(-20) \\
(-170) \\
(+29)\end{array}$ & $\begin{array}{l}606 \\
640 \\
677 \\
625 \\
777 \\
577\end{array}$ & $\begin{array}{l}(-33) \\
(-71) \\
(-19) \\
(-171) \\
(+29)\end{array}$ \\
\hline Mean & 636 & & 665 & & & \\
\hline
\end{tabular}

Note-Mean interference $(-)$ and facilitation $(+)$ scores are shown in parentheses.

Table 2

Mean Reaction Times to Color Naming: Ink Colors, Experiment 1

\begin{tabular}{|c|c|c|c|c|c|c|}
\hline \multirow[b]{2}{*}{ Control } & \multicolumn{2}{|c|}{ Red } & \multicolumn{2}{|c|}{ Green } & \multicolumn{2}{|c|}{ Blue } \\
\hline & 554 & & 648 & & 617 & \\
\hline Neutral Words & 592 & $(-38)$ & 662 & $(-14)$ & 668 & $(-51)$ \\
\hline Incompatible Color Related Words & 590 & $(-36)$ & 737 & $(-89)$ & 706 & $(-89)$ \\
\hline Compatible Color Related Words & 591 & $(-37)$ & 641 & $(+7)$ & 643 & $(-26)$ \\
\hline Incompatible Color Words & 666 & $(-112)$ & 847 & $(-199)$ & 817 & $(-200)$ \\
\hline Compatible Color Words & 532 & $(+22)$ & 613 & $(+25)$ & 587 & $(+30)$ \\
\hline
\end{tabular}

Note-Mean interference $(-)$ and facilitation $(+)$ scores are shown in parentheses. 


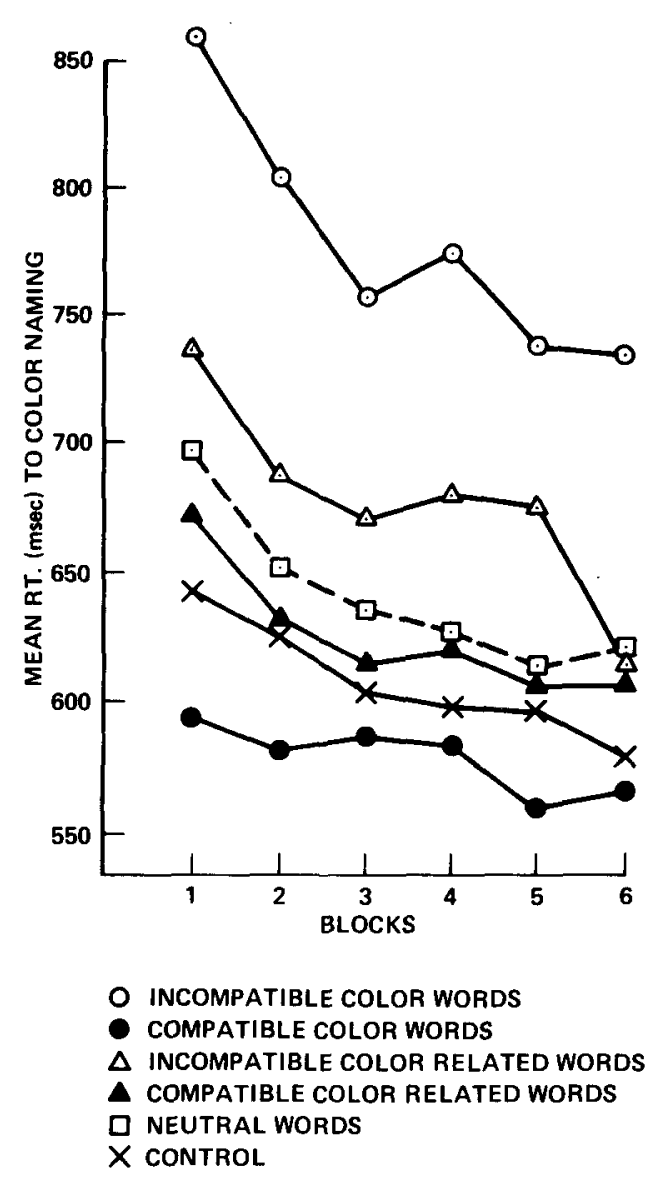

Figure 1. Mean reaction times to color naming as a function of blocks and written item conditions, Experiment 1.

The automatic processing hypothesis predicts that neutral words should delay color naming relative to the control. The 40-msec delay was significant $[F(1,17)=41.83, p<.001]$, indicating that subjects cannot avoid processing the neutral words.

The standard interference effect by incompatible color words was present and naming was also delayed by incompatible color-related words. The Written Item by Ink Color interaction was mainly located in the latter two conditions $[F(2,34)=11.97$ and 16.76 , respectively, $p<.011$. As can be seen in Table 2 , the delay in naming red was about half that for naming blue and green.

When word and color were compatible (e.g., "RED" written in red ink), there was a small $(29 \mathrm{msec})$, but significant, facilitative effect relative to the control Xs $[F(1,17)=10.13, p<.01]$.

The second question to be addressed by this experiment was related to the effect of focal and nonfocal colors. Although the difference speed between these two color types was small $(29 \mathrm{msec})$, it was very reliable (see Table 1). This main effect supports the hypothesis that focal colors are perceptually more salient than nonfocal colors, but there was virtually identical interference and facilitation in the written item conditions, e.g., with incompatible color words focal color naming was delayed $171 \mathrm{msec}$ and nonfocal color naming by $170 \mathrm{msec}$. The only factor goodness of example interacted with was ink color: good blue differed from poor blue [656 vs. $690 \mathrm{msec} ; F(1,17)=13.82, p<.01]$ and good green from poor green [668 vs. $714 \mathrm{msec} ; F(1,17)=22.61$ $\mathrm{p}<.001$ ], but the reds $(582$ vs. $591 \mathrm{msec})$ did not significantly differ from each other $[F(1,17)=3.29]$. Although the differences in red were not signifficant, 13 of the 18 subjects were slower to the poorer reds.

Two other effects are worth noting. In naming blue and red, there was a small amount of interference when a compatible color word was present, ( -37 and $-26 \mathrm{msec}$, respectively), but there was no interference with naming green. This may be because "GRASS" begins with the same initial letters and sounds as the color name. Overall, the ranking of the written item conditions matches that reported by Klein (1964) and is best seen in Figure 1. In general, it appears that, with practice, responding improved in all conditions, with the greatest improvement occurring in the incompatible color-word condition.

The error rate was $2.9 \%$; of these errors, $58 \%$ occurred in the incompatible color-word condition; the next highest error rate was in the incompatible color-related word condition, but was only $2 \%$ of total errors. Fifty-two percent of the total errors were with poor-example colors, but in the incompatible color-word condition there were slightly more errors with focal colors, $32 \%$ vs. $26 \%$.

\section{Discussion}

These data indicate that neutral words can delay the color-naming response, thus providing support for the hypothesis that words are processed automatically, at least in the sense that such processing is involuntary. The data are contrary to the findings of Hintzman et al. (1972), but are in accord with those of Klein (1964).

The good-example colors were responded to faster than the poor examples, although the magnitude of the effect was small $(29 \mathrm{msec})$, but the interference and facilitation effects were virtually identical for focal and nonfocal colors.

Traditionally, investigation of the Stroop phenomenon has asked an either-or question as to whether the effect occurs at the level of response production or at encoding. Several experiments have been designed to show one or the other (e.g., Hintzman et al., 1972; Hock \& Egeth, 1970; Keele, 1972). This question assumes that there is serial processing through independent stages and that the effect is located at either one or the other. In fact, RTs to name a color may reflect a combination of interference and facilitation in a complex but unitary computation. 
The pattern of results shown in Figure 1 suggests that, rather than consider interference or facilitation, there is a dimension of relative ease in processing and responding, with a continuous distribution related to the fit of the written items to the complex computation necessary for producing the color names. In all cases, there is interference, but it is offered by the cognitive system to processing the stimulus, rather than by the stimulus. Within one stimulus, there may be components that fit in readily with the required computation, and other components that do not. For example, "GRASS" has visual and phonetic similarity to "GREEN" in addition to the semantic association, with the result that in the compatible color-related word condition there is less interference to naming green than to naming red or blue, because "GRASS" can be assimilated more readily to the computation required for naming the color green. In the incompatible color-related word condition, "BLOOD" has the same first letters and sounds as blue, although the semantic association is to red. The interference effect of "BLOOD" in naming blue is $45 \mathrm{msec}$, but to naming green is $122 \mathrm{msec}$. [This difference is significant: $t(16)=1.79, p<.05$.] This indicates that the one word, "BLOOD," can provide facilitation and interference simultaneously. In other words, "BLOOD" fits differently into the entire computational context when the task is to name blue than when to name green.

Although the data support the automatic processing hypothesis in that neutral words are processed involuntarily as evidenced by their leading to slower responses than the control, one is left with the uneasy feeling that the distinction between interference and facilitation may be a matter of degree, and that whether one gets interference or facilitation in any experiment is determined by the nature of the control condition. In the present study, if there had been a control of amorphous color patches, rather than Xs, perhaps subjects would have responded faster to these, and the facilitation effect with compatible color words would have disappeared.

\section{EXPERIMENT 2}

Experiment 1 demonstrated that color naming could be delayed by the presence of a word, even when the word was not visually, phonetically, or semantically related to the color names. This finding supports the hypothesis that a familiar word is processed automatically, at least in the sense that its representation is activated involuntarily. However, a previous study (Hintzman et al., 1972) had reported no delay in color naming when neutral words were present. The discrepancy in the two experimental results lies in the nature of the control stimuli. In Experiment 1, the control items were Xs; in the Hintzman et al. study, they were color-word anagrams (e.g., "RDE'). Comparisons of the response times in the two experiments (616 vs. $696 \mathrm{msec}$, averaged over four blocks) suggests that the anagrams may have delayed naming. In both experiments, most of the written items were either color names or words related to colors. It is possible that subjects do not ignore any written item since so many are relevant to the task of saying color names, and that anagrams are processed in their relationship to color words, because that is the way they best fit into the overall processing. This present experiment was designed to test this hypothesis using single letters.

Single letters per se are irrelevant to color naming. If all the stimuli are single letters and the task is to name the color of the ink in which a letter is printed, subjects should be able to ignore the letters. However, if these familiar stimuli are processed automatically, and if those letters that are color-name initials interfere with or facilitate color naming, it would be even stronger evidence in support of the involuntary nature of the processing of familiar items. If such an effect occurs, it would further indicate that, although subjects may not have a choice about whether or not to process a familiar letter, the way such an item is processed may not be determined by some fixed, immutable representation, but rather by the way its processing fits into the overall computation required by the task.

\section{Method}

Design. The design of the experiment was a 3 by 4 by 4 repeated measures factorial, representing three ink colors, four types of written items, and four blocks. The written item conditions were: (1) a digit control (the digit 4), (2) a letter control (six letters chosen randomly: $C, D, K, N, Q, T$ ), (3) color-word initials incompatible with the ink name (e.g., " $R$ " in blue ink), and (4) color-word initials compatible with the ink name (e.g., " $R$ " in red ink).

Materials. Except when indicated, stimuli were prepared as in Experiment 1. The inks used were the good-example colors from Experiment 1. Two decks of cards were assembled with 30 cards per deck. Each of the nine letters and the digit appeared an equal number of times, and once in each ink color. Of the total 30 items in a deck, there were 18 control letters, 3 control digits, 6 letters incompatible with the color names, and 3 letters compatible with the color names.

Procedure. Presentation of the stimuli occurred as in Experiment 1 . The subjects were instructed that they should ignore the written items, as they were irrelevant to their task. They were not provided feedback about their mean RTs during the rest periods.

Subjects. Twelve undergraduates at the University of California, Berkeley, participated in fulfillment of a course requirement. All were naive to color-related tasks and were screened for color blindness.

\section{Results}

Mean RTs for each subject in each condition were computed, and these constituted the basic scores in an analysis of variance. The only significant effects were main effects of written items and ink color $[F(3,33)=19.63, p<.001$, and $F(2,22)=19.49$, 
Table 3

Mean Reaction Times to Color Naming, Experiment 2

\begin{tabular}{lllllllll}
\hline & \multicolumn{2}{c}{ Red } & \multicolumn{2}{c}{ Green } & \multicolumn{3}{c}{ Blue } & \multicolumn{2}{c}{ Mean } \\
\hline Control Digit & 588 & & 684 & & 623 & & 632 & \\
Control Letter & 607 & & 650 & & 652 & & 636 & \\
Incompatible Letter & 662 & $(-55)$ & 716 & $(-66)$ & 696 & $(-44)$ & 691 & $(-55)$ \\
Compatible Letter & 547 & $(+60)$ & 596 & $(+54)$ & 579 & $(+73)$ & 574 & $(+62)$ \\
Mean & 601 & & 662 & & 638 & & 634 & \\
\hline
\end{tabular}

Note-Mean interference $(-)$ and facilitation $(+)$ scores (relative to the letter control) are shown in parentheses.

$\mathrm{p}<.001$, respectively]. The mean RTs for these conditions are shown in Table 3 collapsed over blocks. Comparisons of the written item conditions showed that the two controls did not differ from each other, $F<1$. The incompatible letter condition differed from the letter control $[F(1,11)=8.28, p<.025]$, as did the compatible letter condition $[F(1,11)=$ $154.19, \mathrm{p}<.01]$. Red produced faster responses than blue $[F(1,11)=15.09, p<.01]$, and blue, in turn, was faster than green $[F(1,11)=4.84, p<.05]$.

The mean interference provided by the incompatible letters was $55 \mathrm{msec}$, considerably less than that provided by the incompatible color words in Experiment 1, but more than that with neutral words. The mean facilitation provided by compatible letters was $62 \mathrm{msec}$, more than the $29 \mathrm{msec}$ in Experiment 1 with compatible words.

\section{Discussion}

Although single letters are irrelevant to the colornaming task, these data showed that some of the letters were processed in their relationship to color names. That this processing is involuntary is also supported by the fact that several subjects reported they had no trouble ignoring the letters, were not aware of any interfering or facilitating effects, and did not notice that some letters were color-name initials. (Unfortunately, an exact count of the number of subjects so reporting was not kept.) Unlike the previous experiment which showed a decrease in interference over blocks, a learning effect did not occur here. Since several of the participants seemed unaware of the interference, they probably did not try to overcome it. This may also be a contributory factor to the greater facilitation seen in this study. In the standard Stroop test, subjects probably try to suppress processing the written items as much as they can, and this may mitigate the facilitation effect when compatible color words occur.

Several previous studies have investigated involuntary processing of letters. Eriksen and his colleagues (Eriksen \& Eriksen, 1974; Eriksen \& Hoffman, 1973) have shown that irrelevant noise letters interfere with target detection. The amount of interference was related to the compatibility between responses to the target and responses to the noise items. Keren, O'Hara, and Skelton (1977) showed that the level to which noise letters are processed is determined by the instructions defining level-of-processing target items. The instructions may set up a program or cognitive context in which both the relevant and irrelevant stimuli are processed. Similarly, the data from this experiment suggest that, although familiar letters are processed involuntarily, the way they are processed is not determined by a fixed immutable representation, but rather by the current cognitive context. In this experiment, the cognitive context was related to color naming. Although letters alone may not elicit color names as primary associates, given the color-naming task they are processed in relationship to color names.

The theorists who have compared automatic to attentional processing (LaBerge \& Samuels, 1974; Posner \& Snyder, 1975; Shiffrin \& Schneider, 1977) have suggested that, unlike the latter, automatic processing occurs without either intention or attention. In the standard Stroop task, the subjects are very much aware of the words, and in this sense one would have to say they paid attention to them. One could argue, then, that word processing cannot be automatic in this instance because it occurs attentionally. However, one could also argue that subjects may be attending to the output of the automatic processing, and processing capacity may be involved only in inhibiting the incompatible response, not in encoding the word. In contrast to the position of the automatic processing theorists, Kahneman (1973) has indicated that all processing requires some processing capacity or allocation of resources. Kahneman and Henik (1977) have shown that an irrelevant, unfamiliar Greek letter suffix impairs recall of a series of digits, even though there is no response competition involved. A similar effect was obtained with an irrelevant nonsense form. Kahneman and Henik argue that attentional resources are allocated equally to all items within a perceptual group. Although the interference by words and letters on color naming or by noise letters on letter detection (Eriksen \& Eriksen, 1974; Eriksen \& Hoffman, 1973) or letter matching (Keren et al., 1977) may be primarily related to response selection or production, it is not absolutely clear that the irrelevant item does not also draw on processing capacity for encoding. At the present state of theorizing, it might be better to keep the two asserted characteristics of automatic processing sep- 
arate. Some processes may be involuntary and occur without attention. Some other processes may be involuntary but may usurp attention or processing capacity.

In summary, the data from both these experiments supports the hypothesis that familiar items are processed involuntarily. Both neutral words and incompatible single letters delayed color naming, while compatible words and single letters facilitated naming. There is still no clear choice between the response-conflict and perceptual-conflict interpretations of the Stroop effect. Most of the literature supports the former (see Dyer, 1973, for a review), but this position would seem to imply that the relative speeds of word and color processing are important in determining amount of interference. Manipulating speed of color processing in Experiment 1 did not lead to a change in interference.

The general pattern of results in both experiments indicates that the question of response vs. perceptual conflict may not be an appropriate question. Rather, the written stimuli are processed in the context of generating color names. If the written stimulus can fit into that context readily, responding is relatively fast; if it does not fit in well, responding is slower. The "fit" may related to similarity in responses, visual similarity, semantic similarity, or other, as yet unknown, factors. In Experiment 1, "GRASS" led to less delay in naming green than "SKY" did in naming blue. Naming red led to a different response pattern than naming blue or green, for no obvious reason related to responses, while color-related words also delayed and facilitated naming, presumably because of semantic association to the color names. Thus, it appears that the interference/facilitation effects found with the Stroop task reflect a variety of different factors, not exclusively a response or perceptual conflict.

\section{REFERENCES}

DYER, F. N. The Stroop phenomenon and its use in the study of perceptual, cognitive and response processes. Memory \& Cognition, 1973, 1, 106-120.

Eriksen, B. A., \& Eriksen, C. W. Effects of noise letters upon the identification of a target letter in a nonsearch task. Perception \& Psychophysics, 1974, 16, 143-149.
ERiksen, C. W., \& Hoffman, J. E. The extent of processing of noise elements during selective encoding from visual displays. Perception \& Psychophysics, 1973, 14, 155-160.

HEIDER, E. R. "Focal" color areas and the development of color names. Developmental Psychology, 1971, 4, 447-455.

HEIDER, E. R. Universals in color naming and memory. Joumal of Experimental Psychology, 1972, 93, 10-20.

Hintzman, D. L., Carré, F. A., Eskridge, V. L., Owens, A. M., ShafF, S. S., \& SParks, M. E. "Stroop" effect: Input or output phenomenon. Journal of Experimental Psychology, 1972. 95, 458-459.

Hock, H. S., \& Egeth, H. Verbal interference with encoding in a perceptual classification task. Joumal of Experimental Psychology, 1970, 83, 299-303.

Kahneman, D. Attention and effort. Englewood Cliffs, N.J: Prentice-Hall, 1973.

Kahneman, D., \& Henik, A. Effects of visual grouping on immediate recall and selective attention. In S. Dornic (Ed.), Attention and performance VI. Hillsdale, N.J: Erlbaum, 1977.

Keren, G., O'Hara, W. P., \& Skelton, J. M. Levels of noise processing and attentional control. Journal of Experimental Psychology: Human Perception and Performance, 1977, 3. 653-664.

KEELE, S. Attention demands of memory retrieval. Journal of Experimental Psychology, 1972, 93, 245-248.

KLEIN, G. S. Semantic power measured through the interference of words with color naming. American Journal of Psychology, 1964, 527, 576-588.

KuČERA, H., \& Francis, W. N. Computational analysis of present day American English. Providence, R.I: Brown University Press. 1967.

LaBerge, D., \& Samuels, S. J. Toward a theory of automatic information processing in reading. Cognitive Psychology, 1974, 6, 293-323.

Mervis, C. B., Catlin, J., \& Rosch, E. Development of the structure of color categories. Developmental Psychology, 1975 , 11, 54-60.

Palermo, D. S., \& Jenkins, J. J. Word association norms. Minneapolis: University of Minnesota Press, 1964.

PosNer, M. I., \& SN YDER, C. R. Attention and cognitive control. In R. L. Solso (Ed.), Information processing and cognition. Hillsdale, N.J: Erlbaum, 1975.

Roscr, E. Universals and cultural specifics in human categorization. In R. Brislin, S. Bochner, \& W. Lonner (Eds), Cross-cultural perspectives on learning. New York: Halsted Press, 1975.

Schneider, W., \& Shiffrin, R. M. Controlled and automatic human information processing: I. Detection, search, and attention. Psychological Review, 1977, 84, 1-66.-

ShIfFrin, R. M., \& Schneider, W. Controlled and automatic human information processing: II. Perceptual learning, automatic attending, and a general theory. Psychological Review, 1977, 84, 127-190.

(Received for publication February 14, 1978; revision accepted May 11, 1978.) 